\title{
Plant Growth Promotional Activity of Newly Developed Formulation of Azospirillum on Maize
}

\author{
Geeta Goudar", G. Sreenivasulu, Basamma Kumbar and H. Nagaraj \\ Department of Agricultural Microbiology, College of Agriculture, \\ Vijayapura, UAS, Dharwad, Karnataka, India \\ *Corresponding author
}

\section{A B S T R A C T}

\begin{tabular}{|l|}
\hline Ke y w o r d s \\
Formulation, \\
Azospirillum, \\
maize, PGPR.
\end{tabular}

\section{Keywords}

Formulation, Azospirillum, maize, PGPR.

Accepted:

Available Online:

December 2017
The research work was undertaken to develop solid and liquid based Azospirillum formulations using different additives. It was observed that different additives in the formulation supported the growth of Azospirillum in the formulations. Survivability of Azospirillum formulation in solid/liquid formulations were analyzed by storing them under ambient and refrigerated conditions. Population was estimated at 30, 60, 90, 120 and 180 days after inoculation. Maximum numbers of colonies were observed in liquid based formulations $\left(85 \times 10^{9} \mathrm{cfu} / \mathrm{ml}\right)$. In general the population of Azospirillum was more in the formulations which were stored under refrigerated condition compared to room temperature. The developed formulations were tested on maize for their plant growth promotional activity under pot culture condition. The liquid based Azospirillum formulation $1 @ 5 \mathrm{ml} / \mathrm{kg}$ seed performed better followed by liquid based Azospirillum formulation $2 @ 5 \mathrm{ml} / \mathrm{kg}$ seed. Among the solid talc based formulations, the formulation 3 @ $500 \mathrm{~g} / \mathrm{ha}$ performed better.

\section{Introduction}

Biofertilizers are products of selected beneficial and live microorganisms, which help to improve plant growth and productivity mainly through supply of plant nutrients. Biofertilizers are also known as microbial inoculants or bioinoculants. Biofertilizers play an important role to improve soil fertility and to help plant growth by increasing the number and biological activity of desired microorganisms in the root environment (Sivasakthivelan and Saranraj, 2013). Death of the organisms in the inoculated seeds is one of the important factors contributing the failure of inoculation response in field condition. Research conducted on the inoculant production and formulation technologies is limited. A break through is needed in the inoculation technology to improve the shelf life and field efficacy of biofertilizer in India to make them commercially viable and acceptable to farmers. The present review was focused on different formulations of Azospirillum.

A technical concentrate of an organism that has been achieved by a particular process is called as formulation. There are varieties of formulation viz., liquid and solid. The carrier based bioinoculants generally suffer from shorter shelf life, poor quality, high 
contamination and low field performance. One more problem in inoculants technology is the survival of micro-organisms during storage and several parameters such as culture medium, physiological state of the microorganisms when harvested, the process of dehydrates, rate of drying, the temperature, storage and water activity (Aw) of the inoculums have an influence on their shelf life. So, studies to increase the shelf life of inoculants or finding alternate formulations for carrier based inoculants are important (Chunchun et al., 1998).

Liquid biofertilizer formulation could be considered as one potential strategy for improving the shelf-life of biofertilizer. Unlike solid carrier based biofertilizers, liquid formulations allow the manufacturer to include sufficient amount of nutrients, cell protectant, and inducers responsible for cell/spore/cyst formation to ensure prolonged shelf life (Sivasaktivelan and Saranraj, 2003).

Liquid biofertilizers contains desired microorganisms and their nutrients, special cell protectants or substances that encourage formation of resting spores for longer shelf life and tolerance to adverse conditions.

So the present study was conducted to improve the shelf life and quality parameters of Azospirillum by the addition of suitable additives and also developing new solid and liquid formulations and their role in plant growth promotion under pot culture condition.

\section{Materials and Methods}

\section{Culture collection}

The Azospirillum strain ACD-15 was obtained from the Department of Agricultural Microbiology, University of Agricultural Sciences, Dharwad.

\section{Preparation of formulations}

Three types each of solid and liquid based formulations of Azospirillum were developed using different additives as given below.

Nutrient broth was used as a basal medium for solid (talc) based and liquid based formulation with appropriate concentrations of additives.

\section{Solid (Talc based) formulations of Azospirillum}

Formulation 1 was prepared by inoculating one ml of log phase culture of Azospirillum in the broth with different additives like Tween 80 (stabilizer), Glycerol (osmo-protectent), Trehalose (stabilizer), Sorbic acid (preservative), Potassium sorbate (antifungal agent) and flasks were incubated at room temperature for seven days (Table 1).

Formulation 2 was prepared by inoculating one $\mathrm{ml}$ of log phase culture of Azospirillum in the broth with different additives like Triton X 100 (dispersant), Poly Ethylene Glycol (PEG) (osmo-protectent), Disodium hydrogen phosphate (dispersant), Sorbic acid (preservative), Potassium sorbate (antifungal agent) and flasks were incubated at room temperature for seven days (Table 1).

Formulation 3 was prepared by inoculating one $\mathrm{ml}$ of log phase culture of Azospirillum in the broth with different additives like Tween 20 (dispersant), Poly Vinyl Alcohol (PVA) (osmo-protectent), Citric acid (stabilizer), Sorbic acid (preservative), Potassium sorbate (antifungal agent) and flasks were incubated at room temperature for seven days (Table 1). After incubation, the population of $A$. brasilense was estimated and culture was mixed with talc powder at 1:3 proportions. These formulations were dried and packed in polypropylene bags. 


\section{Liquid formulations of Azospirillum}

Nutrient broth was used as a basal medium for talc based and liquid based formulation with appropriate concentrations of additives.

Formulation 1 was prepared by inoculating one $\mathrm{ml}$ of log phase culture of Azospirillum in the broth with different additives like Tween 80 (dispersant), Glycerol (thickner), Xanthan gum (suspending agent), Sorbic acid (preservative), Potassium sorbate (antifungal agent) and flasks were incubated at room temperature for seven days (Table 2).

Formulation 2 was prepared by inoculating one $\mathrm{ml}$ of log phase culture of Azospirillum in the broth with different additives like Tween 20 (dispersant), Poly Ethylene Glycol (PEG) (thickner), Skimmed milk (suspending agent), Sorbic acid (preservative), Potassium sorbate (antifungal agent) and flasks were incubated at room temperature for seven days (Table 2).

Formulation 3 was prepared by inoculating one $\mathrm{ml}$ of $\log$ phase culture of Azospirillum in the broth with different additives like Triton X-100 (dispersant), Carboxy methyl cellulose (CMC) (thickner), Bentonite powder (suspending agent), Sorbic acid (preservative), Potassium sorbate (antifungal agent) and flasks were incubated at room temperature for seven days (Table 2).

\section{Survivability of Azospirillum in Solid/} Liquid formulations

To study the survivability of Azospirillum in different formulations, the developed solid and liquid formulations and one standard formulation were stored under ambient and refrigerated condition.

Three replications were maintained for each treatment. At monthly interval, the viable counts were determined upto180 days.
Plant growth promotional activity of Azospirillum formulations in Maize under pot culture condition

\section{Preparation of pots}

Red soil collected from the nearby fields of Vijayapura was mixed with sand and farm yard manure (4:1:1) and filled in to pots of 90 $\mathrm{cm}$ diameter at the rate of $6 \mathrm{~kg}$ per bag and were kept in a shade house.

\section{Fertilizer application}

The recommended dose of fertilizer for maize is 25:50:0 NPK kg/ha. Calculated quantities of urea, single super phosphate and muriate of potash were applied on soil weight basis after sowing Azospirillum treated maize seeds. The observation was recorded for plant growth and yield parameters.

\section{Results and Discussion}

\section{Survivability of Azospirillum in Solid/ Liquid formulations}

Results on survivability of Azospirillum in solid and liquid formulations stored under ambient and refrigerated conditions for 30 , $60,90,120,150$ and 180 days are presented in Table 3.

\section{At ambient temperature}

Maximum population of Azospirillum was observed in F5 - LBAF2 $\left(101 \times 10^{9} \mathrm{cfu} / \mathrm{ml}\right)$ followed by F4 - LBAF1 $\left(91 \times 10^{9} \mathrm{cfu} / \mathrm{ml}\right)$ at 30 days after incubation. The population of $10^{9} \mathrm{cfu} / \mathrm{ml}$ was maintained till 120 DAI.

There after there was a gradual decrease in the population. At 180 DAI, maximum population of $57 \times 10^{8} \mathrm{cfu} / \mathrm{ml}$ was recorded in F5 - LBAF2 followed by F4 - LBAF1 (53 $\left.\mathrm{x} 10^{8} \mathrm{cfu} / \mathrm{ml}\right)$. Least population was observed 
in F7 - STBAF (existing) $\left(30 \times 10^{8} \mathrm{cfu} / \mathrm{ml}\right)$ at 180 days after incubation.

\section{At ref rigerated condition}

Population of $10^{9} \mathrm{cfu} / \mathrm{ml}$ was maintained in all the formulations stored under refrigerated condition up to 180 DAI. Maximum population of $96 \times 10^{9} \mathrm{cfu} / \mathrm{ml}$ was observed in F5 - LBAF2 followed by F4 - LBAF1 (85 $\left.\mathrm{x} 10^{9} \mathrm{cfu} / \mathrm{ml}\right)$ at 30 DAI. Thereafter slight decrease in the population was noticed at 150 and $180 \mathrm{DAI}$.

In general, population of Azospirillum was maintained under refrigerated condition than the ambient temperature. Sudden decrease in the population was observed in those formulations which were stored under ambient temperature. Among two types of formulations, the liquid formulation supported more growth of organism.

For the preparation of formulations F4 LBAF1, different additives like Tween 80, Glycerol, Xanthan gum and for F5 - LBAF2, the additives like Tween 20, PEG, Skimmed milk were used.

Various polymers such as PVP, PEG and Gum arabic have adhesive properties. They have sticky consistency, which may enhance cell adherence to seed, and their viscous nature may slow the drying process of the bioinoculants (Temprano et al., 2002).

Similarly, Kumaresan and Reetha (2011) reported that, liquid Azospirillum bioinoculant formulated with Trehalose $(10 \mathrm{mM})$ promoted long term survival of Azospirillum followed by Glycerol $(10 \mathrm{mM})$, Gum arabica $(0.3 \%)$ and PVP (2\%) and they supported $10^{8}$ cells $/ \mathrm{ml}$ up to 11 months of storage under ambient temperature $\left(28^{\circ} \mathrm{C}\right.$ to $\left.32^{\circ} \mathrm{C}\right)$, whereas PEG (1\%), PVA (0.5\%) and control (lignite carrier) recorded the same population up to 8 months, 6 months and 5 months respectively. Liquid inoculants formulated with 2\% Poly Vinyl Pyrollidone (PVP $30 \mathrm{~K}$ ), 0.1\% Carboxy Methyl Cellulose (CMC-high density) and $0.025 \%$ Tween 20 promoted long-term survival of Bacillus megaterium var. phosphaticum, Azospirillum and Azotobacter with population of $5.6 \times 10^{7}, 1.9 \times 10^{8}$ and $3.5 \times 10^{7} \mathrm{cfu} / \mathrm{ml}$, respectively after 480 days of formulation when stored at $30^{\circ} \mathrm{C}$ (Amalraj, 2013).

Higher survival of inoculants was recorded in liquid formulation up to a storage period of 3 month. Better survival of $P$. striata in Glycerol and Tween 20 for longer period was observed and it could be improved by the addition of Skimmed milk and controlled dehydration (Mugilan et al., 2011). Among the different additives, $2.5 \%$ of Glycerol and $2.5 \%$ of Tween 20 was found to record a maximum population of $20.11 \times 10^{9}$ on the $3^{\text {rd }}$ month of storage followed by $2 \%$ of Glycerol and $2 \%$ of Tween 20 . Whereas uninoculated additives (control) recorded only $12 \times 10^{9}$ populations. Carrier based inoculants generally suffer from shortage shelf, poor quality, high contamination and low field performance. The liquid formulations of Azospirillum amended with Trehalose, Poly Vinyl Pyrollidine and Glycerol enhanced and maintained the population level at $10^{8} \mathrm{cfu} / \mathrm{ml}$ up to 10 months of storage (Vendan and Thangaraju, 2006). The formulations shows better adherence and survival on seeds, roots of seedlings and in the rhizosphere soil than the solid carrier based Azospirillum inoculants.

\section{Plant growth promotional activity of Azospirillum formulations in Maize}

Result on effect of different Azospirillum formulations on plant height of maize were recorded at 30, 60 days after sowing and at harvest are presented in Table 4. 
At 30 DAS, highest plant height of $48.2 \mathrm{~cm}$ was observed in T1-STBAF1@500 g/ha (48.2 $\mathrm{cm})$ which is significantly superior over rest of the treatments. The treatments T10LBAF2@5ml/kg seeds $(44.2 \mathrm{~cm})$ and T12LBAF3@5ml/kg seeds $(44.20 \mathrm{~cm})$ were significantly superior over rest of the treatments.

At 60 DAS, the highest plant height was recorded by the treatment T10LBAF2@5ml/kg seeds $(91.0 \mathrm{~cm})$, which is significantly superior over all other treatments. The next highest plant height was noticed in the treatment T8-LBAF1@5ml/kg seeds $(88.3 \mathrm{~cm})$ which is on par with the treatments T5-STBAF3@500g/ha $(86.6 \mathrm{~cm})$ and T11- LBAF2@ 3 ml/ kg seeds (86.30 $\mathrm{cm})$.

Highest plant height at harvest was observed in T10-LBAF2@5ml/kg seeds $(192.00 \mathrm{~cm})$ which is significantly superior over all other treatments. The next highest plant height was observed in T8-LBAF1@5ml/kg seeds (187.3 $\mathrm{cm})$ followed by T5-STBAF3@500g/ha $(185.7 \mathrm{~cm})$, whereas, least plant height was observed in T15-control $(130.3 \mathrm{~cm})$. Results on effect of different Azospirillum formulations on shoot and root dry weight was recorded at 30, 60 days after sowing and at harvest are presented in Table 4.

At 30 DAS, highest shoot dry weight of 15.8 $\mathrm{g}$ was recorded by the treatment T10 LBAF2@ $5 \mathrm{ml} / \mathrm{kg}$ seeds which was significantly superior over rest of the treatments. The treatments T8 LBAF1@5ml/kg seeds (13.7 g/plant), T5 STBAF3@500 g/ha (12.8g/plant) and T11LBAF2@ 3 ml/ kg seeds (12.5 g/plant)were on par with each other.

At 60 DAS, treatment T10 - LBAF2@5ml/kg seeds recorded highest shoot dry weight of $22.7 \mathrm{~g} /$ plant, which was significantly superior over rest of the treatments. The treatments T8 - LBAF1@5ml/kg seeds (19.7 g/plant) and T5 - STBAF 3 @ 500 g/ha (18.6 g/plant) were on par with each other.

Maximum shoot dry weight of $51.6 \mathrm{~g} / \mathrm{plant}$ was recorded in T10 - LBAF2@ $5 \mathrm{ml} / \mathrm{kg}$ seeds at harvest, which was significantly superior over rest of the treatments. The next highest shoot dry weight was recorded in T8 LBAF1@ $5 \mathrm{ml} / \mathrm{kg} \quad$ seeds (48.1 g/plant) followed by T5-STBAF 3 @ 500 g/ha (45.8 $\mathrm{g} /$ plant). Least shoot dry weight was observed in T15 - control (32.0 g/plant).

Insignificant results were observed with respect to root dry weight of plant at 30 DAS.

At 60 DAS, highest root dry weight of $4.6 \mathrm{~g}$ was observed in T10- LBAF2@ $5 \mathrm{ml} / \mathrm{kg}$ followed by T8 - LBAF1@5ml/kg seeds (4.2 $\mathrm{g} /$ plant) which were on par with each other.

Maximum root dry weight of maize at harvest was found in T10 - LBAF2@5ml/kg seeds (5.9 g/plant) which was on par with T8 LBAF1@5 ml/kg seeds (5.8g/plant) and $\mathrm{T}_{5}-$ STBAF 3 @ 500 g/ha (5.6g/plant). Least root dry weight was observed in T15 - control (3.2g/plant).

Result on the effect of different Azospirillum formulations on total dry matter weight was recorded at 30, 60 days after sowing and at harvest and are presented in Table 5.

At 30 DAS, the highest total dry matter weight of $17.6 \mathrm{~g}$ was recorded in $\mathrm{T} 10$ LBAF2@ $5 \mathrm{ml} / \mathrm{kg}$ seeds which were significantly superior over rest of the treatments. The treatments T8LBAF1@5ml/kg seeds (15.4 g/plant), $\mathrm{T}_{5}-$ STBAF3@500g/ha (14.5 g/plant) and T11LBAF2 @ 3 ml/ kg seeds (14.1 g/plant)were on par with each other. 
Table.1 Preparation of Solid (Talc based) formulations of Azospirillum

\begin{tabular}{|c|c|c|c|c|c|}
\hline \multicolumn{2}{|c|}{ Ingredients } & \multicolumn{4}{|c|}{ Composition (\% w/w or v/w) } \\
\hline Filler & Talc & Existing formulation & Formulation 1 & Formulation 2 & Formulation 3 \\
\hline Dispersant & Tween 80 & -- & 3.0 & -- & -- \\
\hline & Tween 20 & -- & -- & -- & 3.0 \\
\hline Osmo-protectant & Glycerol & -- & 1.0 & -- & -- \\
\hline & Poly Ethylene Glycol (PEG) & -- & -- & 1.0 & -- \\
\hline & Disodium hydrogen phosphate & -- & -- & 0.6 & -- \\
\hline & Citric acid & -- & -- & -- & 0.6 \\
\hline Preservative & Sorbic acid & -- & 0.2 & 0.2 & 0.2 \\
\hline Antifungal agent & Potassium sorbate & -- & 0.2 & 0.2 & 0.2 \\
\hline
\end{tabular}

Table.2 Preparation of Liquid formulations of Azospirillum

\begin{tabular}{|l|l|l|l|l|}
\hline \multicolumn{1}{|c|}{ Ingredients } & \multicolumn{3}{c|}{ Composition (\%) w/w or v/w) } \\
\hline Filler & \multicolumn{1}{|c|}{ Talc } & Formulation 1 & \multicolumn{1}{c|}{ Formulation 2 } & \multicolumn{1}{c|}{ Formulation 3 } \\
\hline Dispersant & Culture broth & 95.0 & 95.0 & 95.0 \\
\hline & Tween 80 & 3.0 & -- & -- \\
\hline & Tween 20 & -- & 3.0 & -- \\
\hline Thickener & Triton X 100 & -- & -- & 3.0 \\
\hline & Glycerol & 0.2 & -- & -- \\
\hline Suspending agent & Poly Ethylene Glycol (PEG) & -- & 0.2 & -- \\
\hline & Carboxyl methyl cellulose (CMC) & -- & -- & 0.2 \\
\hline & Xanthan gum & 1.4 & -- & -- \\
\hline Preservative & Skimmed milk powder & -- & 1.4 & -- \\
\hline Antifungal agent & Bentonite powder & -- & -- & 1.4 \\
\hline
\end{tabular}


Table.3 Population of Azospirillum in different formulations stored under ambient and refrigerated conditions

\begin{tabular}{|c|c|c|c|c|c|c|c|c|c|c|c|c|}
\hline \multirow[b]{2}{*}{ Treatments } & \multicolumn{6}{|c|}{ Ambient condition } & \multicolumn{6}{|c|}{ Refrigerated condition } \\
\hline & $\begin{array}{l}30 \text { DAI } \\
\left(x 1^{9}\right)\end{array}$ & $\begin{array}{l}60 \text { DAI } \\
\left(\times 10^{9}\right)\end{array}$ & $\begin{array}{c}90 \\
\text { DAI } \\
(x \\
\left.10^{9}\right)\end{array}$ & 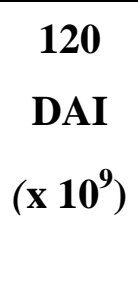 & $\begin{array}{c}150 \\
\text { DAI } \\
(x \\
\left.10^{8}\right)\end{array}$ & $\begin{array}{c}180 \\
\text { DAI } \\
(x \\
\left.10^{8}\right)\end{array}$ & $\begin{array}{l}30 \\
\text { DAI } \\
\quad(x \\
\left.10^{9}\right)\end{array}$ & 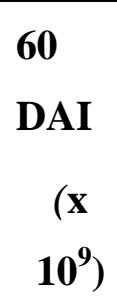 & $\begin{array}{l}90 \text { DAI } \\
\left(x 1^{9}\right)\end{array}$ & $\begin{array}{c}120 \\
\text { DAI } \\
\left(\begin{array}{cc}10 \\
\text { (10) }\end{array}\right.\end{array}$ & $\begin{array}{c}150 \\
\text { DAI } \\
\left(\mathbf{x} 10^{9}\right)\end{array}$ & $\begin{array}{c}180 \text { DAI } \\
\left(x 1^{9}\right)\end{array}$ \\
\hline $\mathrm{F}_{1}-\mathrm{STBAF} 1$ & 73 & 62 & 47 & 40 & 50 & 35 & 78 & 71 & 64 & 60 & 55 & 50 \\
\hline $\mathrm{F}_{2}-\mathrm{STBAF} 2$ & 81 & 71 & 56 & 50 & 55 & 40 & 78 & 74 & 68 & 62 & 57 & 52 \\
\hline $\mathrm{F}_{3}-\mathrm{STBAF} 3$ & 87 & 77 & 60 & 52 & 58 & 53 & 81 & 78 & 72 & 68 & 60 & 58 \\
\hline $\mathrm{F}_{4}-\mathrm{LBAF} 1$ & 91 & 79 & 63 & 58 & 62 & 57 & 85 & 81 & 75 & 70 & 65 & 60 \\
\hline $\mathrm{F}_{5}-\mathrm{LBAF} 2$ & 101 & 84 & 70 & 60 & 57 & 42 & 96 & 92 & 85 & 78 & 67 & 62 \\
\hline $\mathrm{F}_{6}-\mathrm{LBAF} 3$ & 78 & 68 & 55 & 50 & 42 & 35 & 76 & 70 & 63 & 68 & 60 & 54 \\
\hline $\begin{array}{l}\mathrm{F}_{7}-\mathrm{STBAF} \\
\text { (Existing) }\end{array}$ & 69 & 54 & 45 & 40 & 38 & 30 & 66 & 62 & 55 & 50 & 42 & 35 \\
\hline S.Em \pm & 1.90 & 0.9 & 1.07 & 0.67 & 0.63 & 1.03 & 0.86 & 0.82 & 0.89 & 1.00 & 0.78 & 0.49 \\
\hline $\mathrm{CD}(0.01)$ & 5.49 & 2.75 & 3.27 & 2.05 & 1.94 & 3.16 & 2.62 & 2.49 & 2.70 & 3.05 & 2.40 & 1.49 \\
\hline
\end{tabular}

*STBAF- Solid talc based Azospirillum formulations

**LBAF- Liquid based Azospirillum formulations

***DAI- days after inoculation 
Table.4 Effect of different Azospirillum formulations on plant height (cm) and dry matter content (g/plant) of Maize

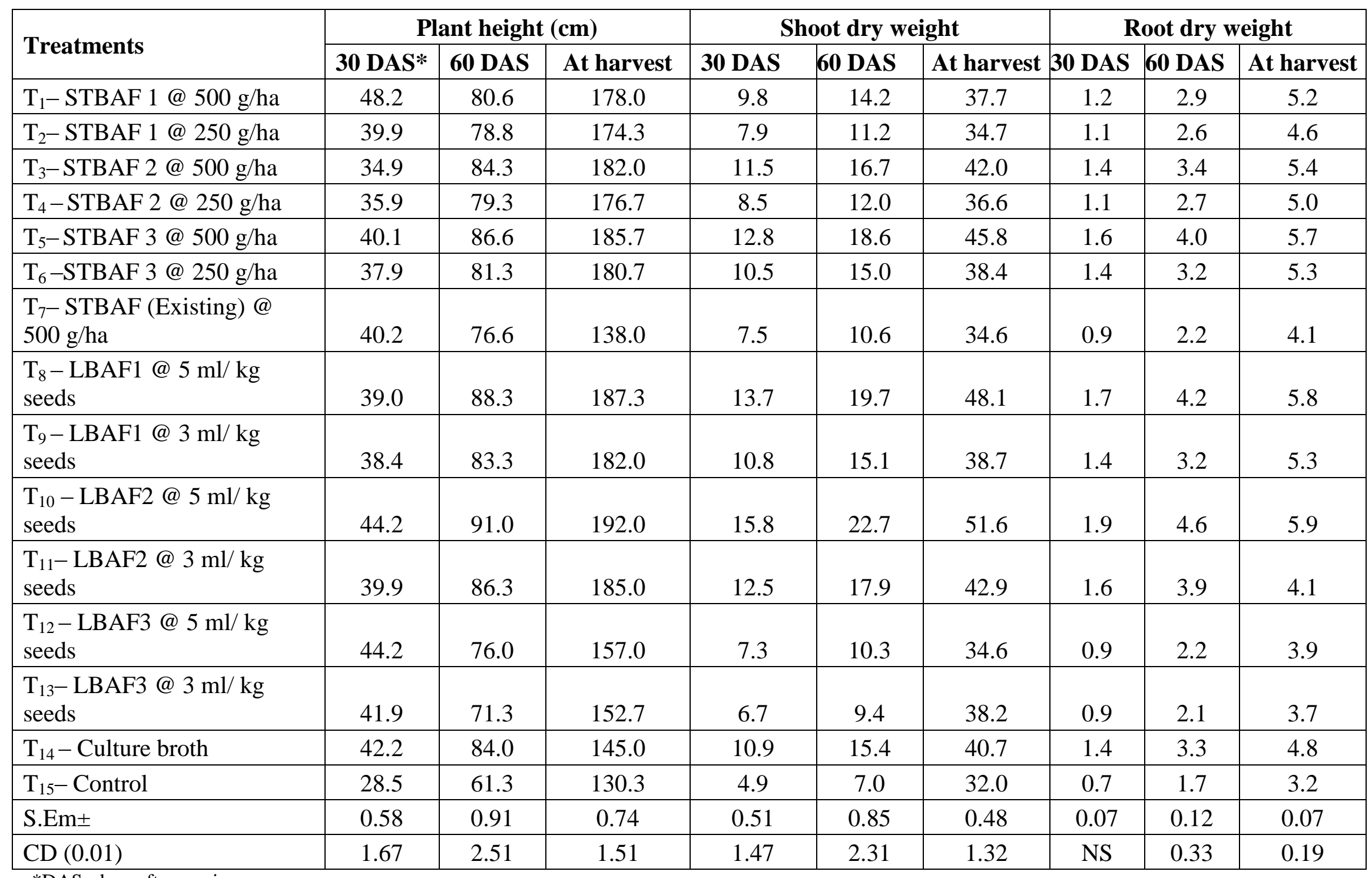

*DAS- days after sowing 
Table.5 Effect of different Azospirillum formulations on total dry matter content (g/plant) and yield of Maize

\begin{tabular}{|c|c|c|c|c|}
\hline \multirow{2}{*}{ Treatments } & \multicolumn{3}{|c|}{ Total dry matter content (g/plant) } & \multirow{2}{*}{$\begin{array}{r}\text { Cob wt } \\
\text { (g/plant) }\end{array}$} \\
\hline & 30 DAS* & 60 DAS & At harvest & \\
\hline T & 11.1 & 17.1 & 42.97 & 129.8 \\
\hline $\mathrm{T}_{2}-\mathrm{STBAF} 1 @ 250 \mathrm{~g} / \mathrm{ha}$ & 9.0 & 13.8 & 39.37 & 126.1 \\
\hline T $3-\mathrm{STBAF} 2$ @ $500 \mathrm{~g} / \mathrm{ha}$ & 12.9 & 20.0 & 47.43 & 136.6 \\
\hline T 4 -STBAF $2 @ 250$ g/ha & 9.6 & 14.7 & 41.59 & 127.6 \\
\hline $\mathrm{T}_{5}-\mathrm{STBAF} 3 @ 500 \mathrm{~g} / \mathrm{ha}$ & 14.5 & 22.6 & 51.43 & 141.3 \\
\hline $\mathrm{T}_{6}-\mathrm{STBAF} 3$ @250 g/ha & 11.9 & 18.3 & 43.71 & 137.8 \\
\hline $\mathrm{T}_{7}-\mathrm{STBAF}$ (Existing) @ $500 \mathrm{~g} / \mathrm{ha}$ & 8.4 & 12.8 & 38.67 & 124.1 \\
\hline $\mathrm{T}_{8}-\mathrm{LBAF} 1 @ 5 \mathrm{ml} / \mathrm{kg}$ seeds & 15.4 & 24.0 & 53.90 & 144.5 \\
\hline $\mathrm{T}_{9}-\mathrm{LBAF} 1 @ 3 \mathrm{ml} / \mathrm{kg}$ seeds & 12.2 & 18.4 & 43.93 & 135.8 \\
\hline $\mathrm{T}_{10}-\mathrm{LBAF} 2 @ 5 \mathrm{ml} / \mathrm{kg}$ seeds & 17.6 & 27.3 & 57.50 & 146.3 \\
\hline $\mathrm{T}_{11}-\mathrm{LBAF} 2 @ 3 \mathrm{ml} / \mathrm{kg}$ seeds & 14.1 & 21.8 & 47.10 & 126.1 \\
\hline T & 8.2 & 12.4 & 38.42 & 124.3 \\
\hline T13-LBAF3@3 ml/kg seeds & 7.6 & 11.5 & 41.90 & 122.3 \\
\hline $\mathrm{T}_{14}-$ Culture broth & 12.2 & 18.7 & 45.56 & 131.5 \\
\hline $\mathrm{T}_{15}-$ Control & 5.6 & 8.7 & 35.20 & 101.9 \\
\hline S.Em \pm & 0.6 & 0.76 & 0.4963 & 0.5 \\
\hline $\mathrm{CD}(0.01)$ & 1.7 & 2.14 & 1.371 & 1.3 \\
\hline
\end{tabular}

*DAI- days after inoculation 
The treatment T10 - LBAF2@5ml/kg seeds recorded the highest total dry matter weight of $27.3 \mathrm{~g}$, which was significantly superior over rest of the treatments. The treatments T8LBAF1@5ml/kg seeds (24.0 g/plant) and $\mathrm{T}_{5-}$ STBAF3@500g/ha (22.6 g/plant) were on par with each other.

Maximum total dry matter content at harvest was found in T10-LBAF2@ $1 \mathrm{ml} / \mathrm{kg}$ seeds (57.5 g/plant) which was significantly superior over rest of the treatments followed by T8LBAF1@ $5 \mathrm{ml} / \mathrm{kg}$ seeds (53.9 g/plant) and $\mathrm{T}_{5}$ STBAF3@500g/ha (51.4 g/plant). Least total dry matter content was found in T15 - control (35.2 g/plant).

Highest cob weight after harvest was found in T10 - LBAF2@5ml/kg seeds (146.3 g/plant) followed by T8 - LBAF1@ $5 \mathrm{ml} / \mathrm{kg}$ seeds (144.5 g/plant) and $\mathrm{T}_{5}-\mathrm{STBAF} 30500 \mathrm{~g} / \mathrm{ha}$ (141.3 $\mathrm{g} /$ plant). Least total dry matter content was found in T15 - control (101.9 g/plant).

Among the different formulations tested, liquid formulation showed the maximum inoculation effect compared to carrier based formulations.

The results are in conformity with the observations made by Mugilan et al., (2011), who reported maximum germination percentage, maximum root length and shoot length of paddy with liquid inoculation of $P$. striata compared to carrier based inoculation. The increased effect of liquid formulation may be due to higher population of $P$. striata. This increase in root colonization as influenced by these cells would increase the density and length of root hairs, as well as the appearance and elongation rate of lateral roots, thus increasing surface area (Fallik et al., 1994).

The bioinoculant treatment of liquid formulation of Azospirillum lipoferum (AUAz$1)+$ Bacillus megaterium (AU Ba-1) + Pseudomonas fluorescens (AU Ps-1) produced the highest recorded values in all growth and yield parameters of sunflower compared with carrier based and alginate bead formulations
(Sivasakthivelan and Stella, 2012).

Inoculation of maize crops with an active strain of $A$. brasilense has a beneficial effect on maize vigour and yield under the identical climatic and soil conditions (Subramanian, 2014).

Inoculation of soil with Azospirillum promoted sheath elongation, root depth, fresh weight of roots, fresh and dry weight of shoots, total nitrogen and bacterial counts in soil. The results showed that wheat inoculated with Azospirillum had a higher growth, mineral and chlorophyll when the plants were not supplemented with nitrogen (Sayed et al., 2015). Inoculation with Azospirillum may improve plant growth and yield by supplementing the growing plants with fixed nitrogen and growth promoting substances (Sumne, 1990).

This increase in yield is also attributed mainly to an improvement in root development, an increase in the rate of water and mineral uptake by roots, and to a lesser extent, biological $\mathrm{N}_{2}$ fixation. A. brasilense shows both chemotaxis and chemokinesis in response to temporal gradients of different chemoeffectors, thereby increasing the chance of root-bacterial interactions. Phytohormones synthesized by Azospirillum influence the host root respiration rate, metabolism and root proliferation and hence better the mineral and water uptake in inoculated plants (Okon and Itzigsohn, 1995).

Azospirillum is one of the important biofertilizer, which is found to fix nitrogen in association with world's most staple food crops like rice, maize, sorghum, wheat and millets (Boddey and Dobereiner, 1988). Formulation of biofertilizer plays a vital role in helping to solve many problems in agricultural field and in making an organism effective in the field. However this must be achieved in a cost effective manner so that product has to survive commercially. Formulation comprises aids to preserving organisms and delivering them to their target fields and once-there to improve their activities (Sivashaktivelan and Saranraj, 2013). A technical concentrate of an organism 
that has been achieved by a particular process is called as formulation. There are varieties of formulation both liquid and solid. The carrier based bioinoculants generally suffer from shorter shelf life, poor quality, high contamination and low field performance. Therefore, it is desirable that new inoculant formulations being developed where liquid inoculants play a significant role.

\section{References}

Amalraj, E.1., B.1.Venkateswarlu, D. Suseelendra, G. Praveen Kumar, S.K. Mir Hassan Ahmed, T. Meenakshi, Uzma Sultana, P. Sravani and Lakshmi Narasu, M. 2013. Effect of polymeric additives, adjuvants, surfactants on survival, stability and plant growth promoting ability of liquid bioinoculants. J Plant Physiology and Pathology. 1:2.

Boddey, R.M., and Dobereiner. 1988. Nitrogen fixation associated with grasses and cereals: Recent results and perspectives for future research. Plant Soil. 108:53-65.

Fallik, E., S. Sarig, and Okon, Y. 1994. Morphology and physiology of plant roots associated with Azospirillum. In Azospirillum/plant associations: CRC Press, Boca Raton, Fla. pp. 77-85.

Kumaresan, G., and Reetha, D. 2011. Survival of Azospirillum brasilense in liquid formulation amended with different chemical additives. Journal of Phytology. 3(10): 48-51.

Mugilan, I., P. Gayathri, E. K. Elumalai and Elango, R. 2011. Studies on improve survivability and shelf life of carrier using liquid inoculation of Pseudomonas striata. International
Journal of Pharmaceutical and Biological Archives. 2(4):1271-1275.

Okon, Y., and Itzigsohn, R. 1995. The development of Azospirillum as a commercial inoculant for improving crop yields. Biotechnology Advances. 13 (3):415-424.

Sayed, E. L., E. A. Hameda and Abdullah, S. 2015. Enhancement of plant growth by soil inoculation with Azospirillum brasilense HM1 isolated from soil of Saudi Arabia. International Journal of Current Microbiology and Applied Sciences. 4(10): 238-248.

Sivasakthivelan, P., and Saranraj, P. 2013. Azospirillum and its formulations: A Review. International Journal of Microbiological Research. 4 (3): 275287.

Subramanian, G., R. Sowmiya, M. Indhu, S. Punitha, J. Sasikala and Jayanthi, V. 2014. Studies on the effect of Azospirillum brasilense on growth parameters in Zea mays Linn. International Journal of Advances in Interdisciplinary Research. 1 (9): 8-11.

Sumner, M. E., 1990. Crop response to Azospirillum inoculation. Advances in Soil Science. 12: 53-123.

Temprano, F.J., M. Albareda, M. Camacho, A. Daza and Santamaría, C. 2002. Survival of several Rhizobium/Bradyrhizobium strains on different inoculant formulations and inoculated seeds. International Microbiology. 5: 81-86.

Vendan, R.T., and Thangaraju, M. 2006. Development and and standardization of liquid formulation for Azospirillum bioinoculant. Indian Journal of Microbiology. 46(4):379-387.

\section{How to cite this article:}

Geeta Goudar, G. Sreenivasulu, Basamma Kumbar and Nagaraj, H. 2017. Plant Growth Promotional Activity of Newly Developed Formulation of Azospirillum on Maize. Int.J.Curr.Microbiol.App.Sci. 6(12): 370-380. doi: https://doi.org/10.20546/ijcmas.2017.612.045 